\title{
Continuidade ou ruptura? Uma análise de alguns aspectos da filosofia social de John Stuart Mill, Alfred Marshall e John Maynard Keynes*
}

\author{
LAURA VALLADÃO DE MATTOS**
}

RESUMO: O artigo argumenta que é possível se falar em uma 'tradição' no campo de filosofia social e econômica unindo as obras de J.S. Mill e Alfred Marshall e J.M. Keynes. Essa 'tradição’ pode ser caracterizada pelas seguintes concepções: (a) pela rejeição moral aos valores aquisitivos do capitalismo; (b) pela visão de que o sistema capitalista seria incapaz de resolver de forma espontânea as questões das desigualdades de renda e riqueza e da pobreza; (c) pela ideia de que, por uma questão de garantia de liberdade e da diversidade, além de por questões de eficiência econômica, dever-se-ia deixar a iniciativa individual agir livremente nas esferas em que é capaz de engendrar bons resultados, mas que o Estado deveria intervir, quando essa falha, atuando em benefício da coletividade; (d) pela crença de que seria possível melhorar significativamente esse sistema por meio de mudanças pontuais e graduais.

PALAVRAS-CHAVE: J.S. Mill; Alfred Marshall; J.M. Keynes; filosofia social e econômica; mudança social.

ABSTRACT: It is argued in this paper that it's possible to speak of a 'tradition' in the field of social and economic philosophy uniting the works of J.S. Mill, Alfred Marshall and John Maynard Keynes. This 'tradition' can be characterized by the following concepts: (a) by the rejection of the acquisitive values of capitalism; (b) by the ideia that capitalism would be incapable of spontaneously solving the problems of distribution of wealth and poverty; (c) by the idea that, for the sake of the preservation of liberty, diversity and economic efficiency, individual initiative should be free to act wherever it engenders good results, but that the State should intervene whenever the free initiative fails, acting in the good of collectivity;

\footnotetext{
* Esse artigo foi desenvolvido como parte das minhas atividades como bolsista de Produtividade em Pesquisa do $\mathrm{CNPq}$ - agradeço o apoio concedido. Uma versão anterior desse artigo foi apresentada no Encontro da ANPEC em 2013. Agradeço o Emmanuel Boff, que debateu o texto no Encontro. Sou grata também ao Maurício Coutinho, ao Danilo Ramalho e à Patrícia Helena Cunha, que gentilmente leram e comentaram o trabalho. Por fim eu gostaria de agradecer os dois pareceristas anônimos da revista, por suas críticas e sugestões.

"* Professora livre-docente do Departamento de Economia da FEA-USP. E-mail: lauramat@uol.com.br. Submetido: 5/Fevereiro/2014; Aprovado: 21/Julho/2014.
} 
(d) by the belief that it would be possible to make capitalism significantly better by the way of small and gradual changes.

KEYWORDS: J.S. Mill; Alfred Marshall; J.M. Keynes; social and economic philosophy; social change.

JEL Classification: B12; B13.

\section{INTRODUÇÃO}

As diferenças existentes entre as concepções de John Stuart Mill, Alfred Marshall e John Maynard Keynes sobre a natureza, o escopo e o método da Economia são marcantes o suficiente para que sejam identificados com três diferentes vertentes da Economia - a Clássica, a Neoclássica e a Keynesiana. Os Princípios de Economia Política de J.S. Mill, publicados em 1848, orientaram por mais de quatro décadas o ensino e a prática dos economistas britânicos. Marshall, com a sua versão do marginalismo, encerra esse domínio em 1890, colocando um fim à Economia Política Clássica e fundando uma nova ortodoxia. J.M. Keynes, por sua vez, revoluciona novamente o pensamento econômico com a publicação Teoria Geral em 1936, e dá início a uma nova 'escola' de pensamento econômico.

No presente artigo argumenta-se, no entanto, que apesar das rupturas no campo da Economia serem, de fato, significativas, há uma continuidade no que tange à filosofia econômica e social desses três autores. Ou seja, quando comparamos os seus posicionamentos no que concerne ao valor do capitalismo como sistema econômico e social, em relação às vantagens e desvantagens do individualismo, às alternativas de organização da sociedade existentes em suas épocas, ou ao tipo de reformas sociais que seriam possíveis e desejáveis, vemos que há inúmeras semelhanças.

Essas similaridades não devem surpreender, uma vez que Marshall foi introduzido à Economia na década de 1860 através da leitura dos Princípios de Economia Política de J.S. Mill e ficou estimulado a estudar economia justamente por esse pensador tratar de uma forma que lhe pareceu interessante a questão das desigualdades sociais existentes (Keynes, [1925] 1966, p. 10). Keynes, por sua vez, aprendeu Economia com Marshall e somente posteriormente se afastou dessa ortodoxia, e certamente era versado nos escritos econômicos de J.S. Mill. ${ }^{1}$ No entanto, apesar de ser razoável esperar que haja uma continuidade, esse aspecto é pouco explorado na literatura, e é justamente essa questão que o artigo visa a explorar.

\footnotetext{
${ }^{1}$ Baldwin (2006) aponta que diferentemente do que ocorre com os escritos econômicos, Keynes quase não faz referência aos escritos mais filosóficos de Mill como o On Liberty, e Utilitarianism. A razão que ele aventa é que a crítica de G.E. Moore ao utilitarismo de Mill fez com que Keynes e boa parte de sua geração acreditasse que a ética desse autor não trazia nada de novo quando comparado ao Bentham. Baldwin considera isso uma pena pois, na sua opinião, Mill apresenta uma reflexão profunda sobre "[...] as dificuldades inerentes a equilibrar uma preocupação com o bem-estar público com a prática de realizações [achievements] individuais criativas” (Baldwin, 2006, pp. 239-240) - tensão também reconhecida por Keynes - e que poderia tê-lo ajudado a construir a sua versão de Liberalismo e a responder a seus críticos.
} 
O alinhamento de J.S. Mill e Alfred Marshall parece ser relativamente natural, dado que eles usualmente são associados à tradição liberal inglesa, entretanto, por conta das suas críticas ao laissez-faire e de sua visão sobre o papel do Estado na economia, Keynes parece se situar em outro terreno. Entretanto, argumenta-se que, apesar de à primeira vista causar estranheza, Keynes pode ser filiado à tradição de filosofia social e econômica de seus antecessores.

Com esse objetivo em mente, o artigo será organizado da seguinte forma: em um primeiro momento, na segunda seção, serão selecionados alguns pontos que considero comuns às abordagens de J.S. Mill e Marshall no que concerne à filosofia social e econômica, ou seja, "construirei” a tradição Mill-Marshall. Em seguida, na terceira seção, serão apresentados elementos que dão sustentação à tese de que é razoável associar Keynes a essa tradição. Por fim, na quarta seção, algumas considerações finais serão apresentadas.

\section{'CONSTRUINDO' UMA TRADIÇÃO: ASPECTOS SELECIONADOS DA FILOSOFIA ECONÔMICA E SOCIAL DE J.S. MILL E ALFRED MARSHALL ${ }^{2}$}

É evidente que para discutir se um autor pertence ou não a uma tradição é preciso primeiro explicitar o que caracterizaria essa tradição. E, para caracterizá-la, selecionei aspectos que dizem respeito não propriamente à teoria econômica dos autores, mas à perspectiva geral que apresentam a respeito do sistema econômico capitalista e sobre como mitigar as eventuais falhas que existam no seu funcionamento. Apesar de todas as diferenças existentes, considero que há alguns elementos básicos que unem as abordagens de filosofia social e econômica de J.S. Mill e Marshall - elementos esses que nos permitem falar em uma perspectiva comum ou em uma 'tradição':

(a) A adoção de um posicionamento moralmente crítico em relação aos valores aquisitivos e egoístas em geral associados ao capitalismo e a concepção de que, após atingido determinado montante de riqueza, o crescimento econômico não deveria ser mais prioridade. $\mathrm{O}$ aumento da riqueza seria apenas um pré-requisito para uma vida melhor, e a Economia seria um instrumento nessa busca. ${ }^{3}$

(b) A visão de que o sistema baseado na propriedade privada e no mercado tem virtudes importantes, mas apresenta igualmente problemas significativos, como engendrar uma distribuição da renda extremamente desigual e condições de vida muito precárias para boa parte da população.

\footnotetext{
${ }^{2}$ Esta seção se apoia em Mattos (1999, 2008, 2011).

${ }^{3} \mathrm{O}$ que cada autor considerava ser uma 'vida melhor' diferia em alguma medida, mas ambos encaram a acumulação de capital apenas como um meio - 'desagradável' — de construir as bases para se chegar a essa situação melhor.
} 
(c) Uma adesão não dogmática ao laissez-faire. Os dois autores tinham uma marcada predileção - por razões econômicas, filosóficas e morais - por deixar aos indivíduos a responsabilidade de resolver os seus problemas pessoais e coletivos. Há, entretanto, igualmente, uma percepção de que o mercado e a iniciativa individual falham em instâncias importantes, e de que, quando isso ocorre, o Estado deve intervir para garantir a obtenção de benefícios sociais e a promoção do progresso.

(d) A crença de que a sociedade pode passar por transformações profundas em sua natureza e vir a se tornar significativamente mais justa e mais feliz por meio de mudanças pontuais, graduais, sem a necessidade de rupturas abruptas ou revoluções nas mais importantes instituições vigentes. ${ }^{4}$

\section{A crítica moral aos valores do capitalismo}

Desde a sua origem a Economia Política foi associada na mente popular aos valores da sociedade capitalista. Os economistas políticos eram acusados de elevar a busca da riqueza e o egoísmo ao status de virtudes e de pregar a acumulação a qualquer custo. No entanto, uma rápida leitura dos escritos de J.S. Mill e de Marshall basta para revelar que esses autores de forma nenhuma apregoavam o tipo de valores associados a eles por seus críticos e, por vezes, até por seus "aliados". De fato, dado o grau ainda incipiente de aprimoramento moral dos seus contemporâneos, esses pensadores consideravam que a busca por riqueza e a competição auto-interessada no mercado tinham uma funcionalidade. E, realmente, apontaram em seus escritos os riscos associados a abrir mão desses incentivos antes que os homens conseguissem alcançar um nível moral de forma a serem motivados por estímulos de ordem mais elevada como, por exemplo, o amor à pátria, o senso do dever, o prazer em fazer o bem (Mill, [1848], 1965, p. 754; Marshall, [1920] 1982, pp. 7-8). No entanto, isso não significa que louvassem os aspectos aquisitivos e autointeressados da natureza humana — que eram os móveis básicos do capitalismo da época - ou que considerassem o aumento da riqueza ou a acumulação de capital a finalidade última a ser buscada pela sociedade.

\footnotetext{
${ }^{4}$ Corry (1978) também tenta traçar uma linha de unidade entre o que ele denomina 'tradição liberal clássica' (que incluiria A. Smith, além de J.S. Mill e Marshall) e Keynes. Para ele, essa 'tradição liberal' defendia as seguintes proposições: 1) que, de forma geral, o mercado seria um mecanismo de alocação eficiente de recursos; 2) que a propriedade privada e o lucro eram ingredientes fundamentais do mercado; 3) que seria desejável melhorar a distribuição de renda e riqueza vigente, contanto que essa melhoria não afetasse a eficiência econômica; 3 ) que a regra no comércio (internacional) deveria ser o livre comércio (Corry, 1978, p. 24). Com base nesses elementos o autor conclui que: "[...] basicamente Keynes queria juntar [wed] o pleno emprego ao liberalismo clássico [...]” (Corry, 1978, p. 25). Vercelli também associa Keynes à tradição liberal (de Smith a Marshall). Para ele, "[...] a intenção de Keynes na TG não era minar o liberalismo econômico, mas resgatá-lo e atualizá-lo” (Vercelli, 2010, p. 73).
} 
J.S. Mill deixa clara nos Princípios a sua discordância moral em relação ao modo de vida levado por seus contemporâneos:

Eu confesso que não me encanto com o ideal de vida abraçado por aqueles que acreditam que o estado normal dos seres humanos é o de lutar para avançar; que o atropelar, esmagar, acotovelar, perseguir os calcanhares uns dos outros, que caracteriza o tipo de vida existente, seja o destino mais desejável para a humanidade [...] (Mill [1848], 1965, p. 754)

O estado ideal para o desenvolvimento do homem e da sociedade seria, segundo ele, "[...] aquele no qual, ao mesmo tempo em que ninguém é pobre, ninguém deseja ser mais rico [...]" (idem). A abstração 'homem econômico', adotada como um instrumento metodológico para investigar a Economia Política de forma semi autônoma em relação à grande ciência social, certamente não refletia os seus valores enquanto filósofo moral. Para Mill, o progresso social em sua sociedade exigia, ao contrário, uma diminuição da intensidade da busca por riqueza entre seus compatriotas:

[...] não é o desejo de riqueza que tem que ser ensinado, mas o uso da riqueza e a valorização de objetos do desejo que não podem ser comprados, e para a obtenção dos quais o dinheiro não é necessário. Todo real melhoramento no caráter inglês, seja incutindo nele aspirações mais elevadas, ou apenas uma avaliação mais correta dos seus objetos de desejo atuais, envolve necessariamente moderar a sua devoção à busca da riqueza. (Mill [1848], 1965, p. 105)

Ele tinha uma imensa crença na possibilidade de aperfeiçoamento humano, e acreditava, que o homem — com a devida educação — seria, no futuro, movido por ideais mais elevados, mais altruístas e menos materialistas (Mill [1873], 1989, p. 176).

Marshall também não se mostrou satisfeito com os valores prevalecentes entre os seus conterrâneos, e era igualmente adepto da ideia de que o homem estaria em processo de aprimoramento moral - e a missão de promover esse melhoramento estava no centro da sua filosofia social.

O autor associava a situação de degradação moral, intelectual e física vigente à situação de pobreza, e por isso a Economia (ao revelar as condições de combatê-la) seria instrumento importante nessa missão (Marshall, [1920], 1982, p. 3; Reisman, 1987, p. 4). Como observa Viner:

[...] O progresso que ele [Marshall] buscava [...] não era meramente uma questão de mais bens, mas de acesso a, e gosto por, mais lazer, a uma vida mais refinada para todas as pessoas, de forma que até os carregadores de varas pudessem ser gentlemen. [...] (Viner, 1958, p. 250).

Em várias passagens da sua obra podemos ver que Marshall também desejava ver outro conjunto de valores prevalecendo na sua sociedade. $\mathrm{O}$ autor louvou repe- 
tidamente a mudança de valores sociais que, segundo ele, teria ocorrido ao longo do século XIX e que levou a um controle social dos aspectos mais perversos da concorrência e a uma valorização por parte da sociedade de outros fins sociais além do crescimento da riqueza (Marshall, [1920], 1982, pp. 620-1 e Mattos, 2011). Todavia, apesar de apontar essas melhorias morais e sociais, ele demandou de seus contemporâneos maior ética no agir econômico (que ele denomina 'economic chilvrary') que envolveria nobreza, lealdade, altruísmo e a valorização da riqueza, não como um fim em si, mas como um indício de sucesso e de distinção (Marshall, [1907 1966], p. 331). Essa mudança de valores significaria igualmente um aumento de responsabilidade e da participação dos ricos na resolução dos problemas sociais mais gerais.

Para Marshall, tal como para J.S. Mill, o aumento de riqueza já não deveria ser prioritário (pelo menos na Inglaterra)..$^{5}$ Para livrar os homens de trabalhos rudes que brutalizavam a sua natureza, e para aumentar o tempo de lazer da classe trabalhadora como um todo, Marshall estava, inclusive, disposto a defender uma redução (moderada) da jornada de trabalho (Marshall, [1873], 1966). Em princípio, isso não necessariamente implicaria queda de produto, uma vez que uma vida melhor e mais saudável também teria impactos positivos sobre a produtividade do trabalho, no entanto, por uma vida mais elevada, na qual todos pudessem ser gentlemen, Marshall certamente estaria disposto a sacrificar alguma riqueza material. ${ }^{6}$

Marshall explicita uma preocupação, já presente em J.S. Mill, e que voltará em outra forma na teoria do Keynes, com como os indivíduos usam o seu tempo livre. Ele afirma: "Em todas as épocas e em todas as nações, aqueles que sabem como trabalhar bem sempre foram bem mais numerosos do que aqueles que sabem utilizar bem o lazer" (Marshall, [1920], 1982, p. 599). Uma verdadeira melhoria teria que passar por mudanças profundas nos hábitos e nos valores da sociedade.

Fica claro, assim, que o 'homem ideal' de Marshall estava longe de ser o homem aquisitivo e moralmente degradado de sua época. Seria, ao contrário, um homem com valores nobres, usualmente pouco associados à ordem de mercado, e similares, em parte, aos exaltados pelos autores românticos — talvez os maiores críticos morais à economia na época (Grampp, 1972).

\footnotetext{
${ }^{5}$ Ao se referir à situação de seu país, Marshall afirma: “[...] a nação já cresceu em riqueza, em saúde, em educação e moralidade; e não somos mais compelidos a subordinar quase todas as considerações à necessidade de aumentar o produto total [...]"(Marshall, [1920], 1982, p. 621).

${ }^{6}$ Para Marshall o 'mero' aumento de riqueza não era suficiente para que os homens se desenvolvessem e vivenciassem uma condição melhor. Ele apresenta uma distinção importante entre um aumento no 'padrão de vida' (standard of life), - que "[...] implica um aumento na inteligência, energia e autorrespeito, levando a mais cuidado e julgamento nos gastos, e a um evadir-se de comidas e bebidas que satisfazem os apetites, mas que não fornecem força, e de modos de vida que são pouco saudáveis física ou moralmente" (MARSHALL, 1982, p. 574) — e aumentos no do que 'padrão de conforto' (standard of comfort). Como fica claro na citação, um aumento no 'padrão de vida' significaria algo mais do que um aumento de riqueza ou de acesso a bens. Importava, para Marshall, não só o nível de consumo, mas a composição desse consumo. Nesse sentido, faria toda a diferença o homem estar utilizando a sua remuneração adicional para aumentar o seu consumo de álcool, ou para substituir essa bebida por chá.
} 
Dessa forma, no que concerne à avaliação geral sobre a ordem vigente, vemos que tanto J.S. Mill como Marshall apresentaram uma condenação moral ou, pelo menos, pouco entusiasmo em relação a vários valores associados ao capitalismo. A motivação egoísta de busca pela riqueza era vista por ambos como temporariamente útil, mas certamente não representava o 'melhor' do ser humano. Seria algo a ser superado, ou, pelo menos, bastante reduzido, com o aprimoramento dos homens e o melhoramento da sociedade, e substituído por valores menos materialistas, mais cooperativos, sociais e altruístas.

\section{Críticas à distribuição de renda e riqueza prevalecentes}

Outro aspecto que permite traçar uma linha de continuidade entre as concepções de J.S. Mill e Marshall é a manifesta insatisfação desses autores com o status quo. Apesar de defenderem em linhas gerais a manutenção do sistema de propriedade privada e de iniciativa individual, de forma nenhuma consideravam o estado vigente adequado, justo ou louvável. Os dois apontaram inúmeros problemas no sistema, principalmente no que dizia respeito à enorme desigualdade na esfera da distribuição da riqueza e da renda na sociedade, e à existência de um grande contingente de pessoas vivendo em situações bastante degradadas. ${ }^{7}$

No que se refere à distribuição, J.S. Mill considerava a situação de injustiça tão gritante que tornava "[...] a ideia de justiça distributiva [...] no presente estado de sociedade, tão quimérica que pertence somente ao terreno da ficção [...]” (Mill, [1879], 1967, p. 714). Para ele, não existiria "[...] qualquer proporcionalidade entre sucesso e mérito, ou entre sucesso e esforço [...]” (idem).

A miséria e as péssimas condições de vida de boa parte da classe trabalhadora também incomodavam sobremaneira o autor. Influenciado pela teoria malthusiana da população, J.S. Mill considerava que, em última instância, o aumento desenfreado da população era o grande responsável pela pobreza. O caminho, portanto, para uma situação melhor envolveria certamente um equacionamento da questão populacional - sem o qual nenhum esquema concebível poderia gerar resultados duradouros. Exigiria, igualmente, melhoria significativa na distribuição renda e riqueza na sua sociedade - tornando-a mais justa.

Nos seus Princípios, J.S. Mill propõe uma extensa agenda de reformas que almejava corrigir a situação de pobreza e iniquidade que existia na sua sociedade. Entre as mais importantes podemos citar políticas educacionais, políticas de amparo aos pobres, reformas nas leis de herança, na forma de apropriação da terra e nos contratos (Mattos, 2008).

Marshall também se preocupou muito com os problemas de má distribuição

\footnotetext{
${ }^{7}$ Vale ressaltar que para os autores o conceito de igualdade relevante era o de igualdade de oportunidade. A existência de desigualdades sociais seria aceitável contanto que decorrente de diferenças no grau de interesse pela riqueza, nos esforços ou nos méritos individuais. Mas ambos consideravam as desigualdades existentes bem maiores do que as seriam justificáveis por conta dessas diferenças.
} 
de riqueza e renda e de pobreza vigentes em sua sociedade. No seu entender, as desigualdades eram demasiadamente grandes, e seria possível manter o estímulo à iniciativa e ao empenho com ganhos bem menores. ${ }^{8}$ Para ele, "[...] não há nenhuma necessidade e, portanto, nenhuma justificativa moral para existência de pobreza lado a lado à enorme riqueza [...]" (Marshall, [1920], 1982, p. 594). Assim, podemos dizer que o combate à pobreza e às grandes desigualdades sociais foram também prioridades assumidas por esse pensador, e eram peças fundamentais no seu projeto de melhoramento da sociedade. ${ }^{9}$

O seu diagnóstico sobre as causas da pobreza era, no entanto, diferente daquele de J.S. Mill. Para Marshall, existiria um círculo vicioso, no qual a pobreza gerava as condições que acabavam por perpetuar a situação de miséria. Para ele, "[...] a pobreza do pobre é a principal causa daquela fraqueza e ineficiência que são as causas da sua pobreza"(Marshall apud Reisman, 1987, p. 205).

Também Marshall apresentou várias propostas de reformas econômicas e de políticas sociais que visavam a quebrar esse círculo vicioso da pobreza e desigualdade. Entre outras coisas, propôs a cobrança de imposto sobre herança, o imposto de renda progressivo, ${ }^{10}$ mudanças nos valores e gastos da população (principalmente redução de gastos em bens posicionais por parte dos ricos), o aumento do cavalheirismo econômico, e a utilização da riqueza assim captada em investimentos maciços na educação, em combate direto à pobreza, em regulamentação de moradias, e em investimento em áreas e parques públicos, na melhoria da qualidade do ar, na garantia de acesso da população em geral às artes, etc. (Marshall, [1907], 1966, p. 54, Marshall, [1920], 1982, pp. 597 e 599; Groenewegen, 1995, p. 150; Marshall, [1889], 1966, p. 228-9).

Assim, tanto J.S. Mill como Alfred Marshall estavam mobilizados em alterar as condições de suas respectivas sociedades — principalmente em melhorar a condição dos trabalhadores pobres e dos excluídos. Eles viam muitas falhas que o mercado e a livre iniciativa sozinhos não davam conta de resolver, e não relutaram em demandar um papel mais ativo para o Estado no sentido de mitigá-los.

\footnotetext{
8 "O progresso econômico requer como condição livre responsabilidade individual, mas não a manutenção daqueles direitos de propriedade que acarretam desigualdades extremas de riqueza" (Marshall, 1890, p. 282).

${ }^{9}$ Marshall buscou a Economia Política com o objetivo de entender e minorar as desigualdades e o sofrimento social. E ele perseguiu esse objetivo de forma consistente por toda a sua vida. Em 1893, ele fez a seguinte declaração para a Royal Commission on the Aged Poor: "Eu me devotei nos últimos 25 anos para o problema da pobreza e [...] muito pouco do meu trabalho foi devotado para qualquer investigação que não tenha relação com isso" (Marshall apud, Hutchison, 1969, p. 247).

${ }^{10}$ Bowman (2004, p. 514) aponta que Marshall era inicialmente contra o imposto sobre herança, pois temia que este diminuísse a motivação e o crescimento econômicos, no entanto, posteriormente, passou a apoiar esse tipo de iniciativa. Groenewegen relata uma reação parecida de Marshall no que diz respeito à taxação redistributiva com alíquotas progressivas. Inicialmente ele apresentou restrições a esse tipo de ação por julgar que poderia prejudicar o trabalho e a poupança, mas, posteriormente, passou a considerar que "[...] tais taxas eram um instrumento útil de politica social, especialmente se seus proventos fossem gastos de maneira satisfatória [...]” (Groenewegen, 1995, p. 150).
} 


\section{Perspectiva geral sobre o mercado, a iniciativa individual e o papel do Estado - uma adesão não dogmática ao laissez-faire}

É possível argumentar que existe também uma linha de continuidade entre J.S. Mill e Marshall no que concerne à posição que assumem em relação ao papel do Estado. Como mencionado, os dois autores são associados ao liberalismo econômico e, de fato, advogaram, em linhas gerais, o laissez-faire como a melhor política a ser adotada por suas respectivas sociedades. Entretanto, essa defesa não foi de forma alguma dogmática - eles explicitamente combateram a ideia de Estado Mínimo e, mesmo quando trataram da Inglaterra, fizeram questão de explicitar uma lista (extensa) das instâncias nas quais o mercado e a livre iniciativa não geravam resultados socialmente benéficos, fazendo-se necessária a intervenção ativa do Estado (Mill, [1848], 1965, livro V, cap. XI; Marshall, [1907], 1966).

A defesa da livre iniciativa possuía, nesses autores, fundamentos econômicos e filosóficos. Por um lado, eles tinham grande confiança na capacidade de o mercado e a iniciativa individual resolverem boa parte dos problemas econômicos especialmente no que dizia respeito à esfera da produção de riqueza. ${ }^{11}$ Por outro, eles consideravam que deixar aos indivíduos a responsabilidade de tentar equacionar os seus problemas pessoais e coletivos seria benéfico para o desenvolvimento das suas faculdades morais e intelectuais. Consideravam também que o sistema de livre iniciativa era a melhor garantia da manutenção da liberdade e da diversidade - fundamentais, no entender desses pensadores, para o progresso econômico e social (Mill, [1848], 1965, pp. 942-944 e 517; Parsons, 1931, pp. 126-8, Marshall, [1907], 1966, pp. 333-4).

No entanto, apesar dessa marcada predileção apontaram, como mencionado, várias instâncias nas quais a iniciativa individual e o mercado não engendravam resultados socialmente bons, como, por exemplo, na educação e no combate à pobreza - e, onde o mercado falhava, o Estado teria o dever de atuar para promover o benefício social. ${ }^{12}$

Assim, as abordagens de J.S. Mill e de Marshall em relação à questão da fron-

\footnotetext{
${ }^{11}$ No entanto, nem tudo nessa esfera seria bem solucionado pela iniciativa individual. Eles citam, por exemplo, a necessidade de intervenção estatal no caso de fornecimento de bens que são produzidos sob condições de monopólios naturais, ou que envolvem indivisibilidade de capital; de bens socialmente úteis, mas que não rendem lucros privados suficientes para que haja provisão adequada; defenderam também a necessidade de proteção (temporária) à indústria nascente, entre outros tipos de intervenção.

12 Outros casos nos quais o Estado é chamado a atuar são: cuidar de loucos e crianças, assegurar o cumprimento de contratos, garantir a defesa nacional e a justiça, regular condições de habitação urbana, planejamento das cidades, políticas de colonização, difundir informações, etc. Ao tratar de sociedades mais atrasadas temos uma noção melhor da medida na qual J.S. Mill estava disposto a abrir mão do laissez-faire. Ele afirma: "[...] Nas circunstâncias específicas de uma determinada época ou nação, dificilmente há alguma coisa realmente importante para o interesse geral que não possa ser desejável, ou até mesmo necessário que o governo assuma" (Mill, [1848], 1965, p. 547). J.S. Mill faz, entretanto, a ressalva de que o Estado deveria estar preocupado em preparar esse povo para, em um momento posterior, passar a desempenhar essas tarefas (idem, p. 548).
} 
teira entre o Estado e mercado apresentam, no meu entender, traços semelhantes, sendo bastante flexíveis e, em certo sentido, pragmáticas. Apesar de o ponto exato onde cada um traçou a linha de demarcação ter sido diferente, considero que o critério adotado foi o mesmo: onde a intervenção estatal se fizesse necessária por conta de 'falhas de mercado' e produzisse mais bem do que mal, ela seria bem-vinda; nas demais esferas da vida social — por questões de eficiência econômica, e de garantia de liberdade e diversidade - o ideal seria garantir o espaço para a escolha e iniciativa individuais. Neste aspecto, também, acredito ser possível considerar esses dois autores como membros de uma mesma tradição de pensamento.

\section{Anseio de modificar a sua sociedade de forma profunda, porém gradual e, na medida do possível, voluntária}

Outro aspecto em que acredito existir uma linha de continuidade entre as posturas dos dois autores diz respeito ao posicionamento que assumem no campo da mudança social. Embora críticos a vários traços da sociedade da época, as propostas de reforma social de J.S. Mill e Marshall primavam pela rejeição a alternativas radicais ou abruptas ao estado vigente. Ambos gostariam de ver o tipo de capitalismo vigente em suas respectivas épocas modificado, mas acreditavam que a forma mais adequada de melhorar o sistema era manter-se no âmbito do mercado - e essa posição fundamentava-se somente em parte em questões relacionadas com a eficiência econômica.

O sistema de livre iniciativa parecia aos autores mais propício para a manutenção das energias e das atividades humanas e mais compatível com a liberdade e com a garantia de diversidade - características consideradas fundamentais para a continuidade do progresso social - do que as formas de socialismo que se apresentavam como alternativas. ${ }^{13} \mathrm{~A}$ eliminação da competição no mercado e da iniciativa privada também não era bem-vinda, pois isso poderia levar ao risco de estagnação em termos tecnológicos. ${ }^{14}$

Assim, o que desejavam era transformar significativamente a natureza do sistema, sem solapar ou revolucionar as suas bases — ou seja, ambos apresentavam uma

\footnotetext{
${ }^{13}$ Vale notar que o termo 'socialismo' significa coisas diferentes para J.S. Mill e Marshall. J.S. Mill discute de forma mais detida e respeitosa as sugestões dos 'socialistas utópicos' - owenistas, saintsimonianos, fourierianos, e não presta muita atenção às propostas revolucionárias de mudança social (Mattos, 1999). Os socialistas de Marshall eram, por sua vez, aqueles que defendiam propostas de centralizar os meios de produção nas mãos do Estado. Para ele, o socialismo era "[...] um movimento para tirar a responsabilidade pela vida do homem e por seu trabalho, tanto quanto possivel, dos seus ombros e colocá-los nos ombros do Estado [...]" (Marshall apud Reisman, 1987, p. 122). Para uma análise detalhada do que Marshall entendia por socialismo e das principais críticas direcionadas por ele a esta alternativa ver Reisman (1987, pp. 121-127).

${ }^{14}$ Apesar de estes elementos aparecerem nos dois autores, a ênfase de J.S. Mill recai sobre a questão da liberdade/diversidade (Mill, [1848] 1965, p. 209; Mill [1859], 2000; Mattos, 1999) enquanto a de Marshall sobre a questão do risco à inovação num contexto em que grandes burocracias estatais dominam a produção (Marshall, [1907], 1966, p. 333; Mattos, 2011).
} 
abordagem reformista à mudança social. Eles acreditavam que reformas pontuais bem aplicadas no sistema de propriedade privada e livre iniciativa poderiam levar a uma profunda, apesar de gradual e, em alguma medida voluntária, modificação social.

J.S. Mill — talvez mais radical do que Marshall na sua utopia — vislumbra uma situação na qual a sociedade caminharia, vagarosa e espontaneamente, em direção a uma sociedade de cooperativas (Mattos, 2008):

[...] os donos do capital iriam gradualmente percebendo como sendo de seu interesse [...] emprestar seu capital às associações; fazê-lo a taxas de juros cada vez mais baixas, e por fim, talvez, até trocar os seus capitais por anuidades [terminable annuities]. (Mill, [1848], 1965, p. 794).

A modificação final seria bastante expressiva. Por meio de um processo pacífico e voluntário, o trabalho assalariado seria paulatinamente extinto, o caráter do sistema modificado e uma nova ordem surgiria. Neste novo arranjo social combinar-se-ia a independência dos indivíduos e a vantagem da produção em larga escala, e todas as diferenças sociais, exceto as derivadas de diferenças nos empenhos ou nas contribuições individuais, seriam extintas (Mill, [1848], 1965, p. 793). Essa ordem de coisas certamente seria mais eficiente, mais justa e mais adequada para a continuidade do progresso humano e social do que aquela vigente na época. E, para Mill, constituiria " [...] a solução mais próxima à justiça social, bem como o sistema industrial mais benéfico para o bem universal que se possa hoje prever" (Mill, [1848], 1965, pp. 793-4).

A sociedade almejada por Marshall teria um caráter distinto daquela de J.S. Mill, no entanto, seria também algo bem diferente e superior ao que ele via em sua época. O caminho para uma situação melhor seria impulsionado por algumas ações pontuais do Estado, e por uma ampla mudança nos valores da sociedade (principalmente pelo aumento do cavalheirismo econômico). À semelhança de J.S. Mill, Marshall também se mostrou cético em relação às soluções repentinas e abruptas. A epígrafe que ele escolhe para os Princípios - "Natura non facit saltum" - representa bem a sua visão no que concerne às mudanças sociais. O que ele buscava eram alterações persistentes e contínuas que ao final de um período de tempo produzissem as melhorias desejadas nas condições de trabalho e de vida dos homens. Essas modificações já estariam sendo produzidas pelo próprio evoluir do capitalismo, e poderiam ser estimuladas por uma atuação ativa do Estado e da sociedade no sentido de superar os problemas pontuais (mas sérios) que o sistema de liberdade econômica não dava conta de resolver sozinho.

O caminho para essa sociedade melhor seria também gradual, contínuo, voluntário e, em grande medida, espontâneo. Sem alterações radicais nas instituições sociais existentes, chegar-se-ia a uma situação verdadeiramente justa e feliz:

Sob tais condições as pessoas iriam em geral ser tão bem nutridas e tão verdadeiramente educadas que a terra seria um lugar agradável de viver. Os salários seriam altos por hora, mas o trabalho não seria caro. O capital não estaria ansioso para emigrar dele, mesmo que pesados im- 
postos fossem recolhidos para finalidades públicas [...]; e assim um verdadeiro socialismo, baseado em cavalheirismo, surgiria [...]. Socialismo Nacional desta espécie pode ser cheio de individualidade e elasticidade [...] (Marshall, [1907], 1966, pp. 345-6).

A utopia de J.S. Mill envolve, em última instância, mudanças mais profundas no sistema, uma vez que na sua sociedade ideal não existiria mais trabalho assalariado. A ambição de Marshall parece ser chegar a um capitalismo civilizado e moralizado - moderado pela ação do Estado e da opinião pública - no qual não existiriam formas degradantes de trabalho, mas onde persistiria a relação assalariada. Esse seria um sistema no qual todos poderiam desfrutar de forma mais equitativa dos ganhos gerados, mas onde continuariam vigorando (apesar de reformadas) as principais instituições então vigentes (Mattos, 2011, pp. 657-8).

De qualquer forma, como enfatizado, a perspectiva de reforma gradual, lenta e sem rupturas do sistema vigente prevalece em ambos - o que torna possível alinhar os dois autores também no que concerne a este ponto.

\section{KEYNES: RUPTURA OU CONTINUIDADE EM RELAÇÃO À TRADIÇÃO DE J.S. MILL?}

Keynes rompe, como mencionado anteriormente, com aqueles que ele denomina "Clássicos" - entre os quais inclui J.S. Mill e Marshall — no que concerne à sua visão do funcionamento do sistema econômico, aos determinantes do nível de emprego e produto, e a várias outras questões que caem no âmbito da teoria econômica propriamente dita. Também difere no papel que considera que o Estado deve assumir vis-à-vis ao mercado. Por essas razões, em geral, a ênfase dos comentadores (e do próprio Keynes) recai sobre os pontos que o separam dos economistas que o antecederam. Todavia, defendo que, no que diz respeito aos aspectos de filosofia econômica e social tratados, é possível traçar uma linha de continuidade entre as concepções de Keynes e as da tradição que o precede. O restante dessa seção busca apresentar elementos para sustentar essa interpretação. ${ }^{15}$

\footnotetext{
${ }^{15}$ Keynes discute os temas aqui tratados em diversos textos e nem todos com a mesma densidade teórica. $\mathrm{E}$, tal como fazem os demais comentadores que discutem filosofia social de Keynes, utilizo trechos tirados da Teoria Geral ao lado de evidências obtidas em textos de divulgação, cartas, artigos políticos, textos de 'ocasião', etc. Como apontou o parecerista anônimo da revista, essa conduta pode ser problemática. No entanto, considero que há boas justificativas para adotá-la. A principal delas é a de que se analisarmos apenas os textos teoricamente mais densos e robustos do autor, teremos pouco a dizer sobre esse aspecto (importante) do seu pensamento. Considero também que o fato de as concepções de Keynes, no campo de filosofia social, apresentarem uma admirável consistência ao longo do tempo dá certa legitimidade ao procedimento. As ideias apresentadas pelo autor nos seus textos menos densos, ou de persuasão, reforçam e complementam as concepções expostas nos seus textos mais acadêmicos.
} 


\section{Keynes e os valores do capitalismo ${ }^{16}$}

A postura de Keynes em relação ao capitalismo pode ser considerada ambígua. Ao mesmo tempo em que buscou incessantemente mecanismos que fossem capazes de fazer com que capitalismo funcionasse melhor (e de ter bem-sucedido nessa busca), ele se mostrava extremamente crítico em relação aos valores subjacentes a esse sistema. ${ }^{17} \mathrm{E}$ nisso, podemos afirmar que ele segue a tradição de seus predecessores.

Keynes deixa explícita a sua aversão a vários dos princípios morais e motivações mais característicos do capitalismo - em especial a motivação por busca de riqueza, a louvação da poupança e da acumulação de capital - e à ênfase quase exclusiva dada a esses valores na sua sociedade. Ele afirma:

$[\ldots]$ o problema moral da nossa época diz respeito ao amor ao dinhei-
ro, ao apelo habitual à motivação monetária [...], à busca universal por
segurança econômica como o objetivo básico do empenho, à aprovação
social do dinheiro como medida do sucesso construtivo, e ao apelo ao
instinto de entesouramento como a fundação para a necessária provisão
para a família e para o futuro.[...]." (Keynes, [1925a], 1972, pp. 268-9,
ênfase adicionada). ${ }^{18}$

Nas suas críticas à intensidade do 'amor ao dinheiro' e à tendência da sociedade a atribuir peso excessivo ao dinheiro como medida do sucesso, Keynes não foge à tradição de J.S. Mill e Marshall, que também desejavam ver a motivação 'busca por riqueza' reduzida nos seus contemporâneos e almejavam por transformações nos valores sociais. No entanto, a sua rejeição aos valores vitorianos de frugalidade e previdência é um elemento importante que o separa de seus antecessores, que viam no comedimento, na prudência e na responsabilidade em relação ao futuro qualidades morais fundamentais, a serem cultivadas na natureza humana.

Para Keynes, a ideia de poupar para ter mais e mais no futuro, e, por vezes, nem

\footnotetext{
${ }^{16}$ Todas as referências do Keynes têm a paginação dos Collected Writtings of John Maynard Keynes - que é a edição consagrada da obra do autor. No entanto, no caso dos textos "The Economic Possibilities of our Grandchildren" e "The End of Laissez-faire”, utilizei a tradução de Miriam Moreira Leite que se encontra no livro John Maynard Keynes: Economia. Org. T. Szmrecsányi. São Paulo, Editora Ática, 1984.

${ }^{17}$ As concepções morais de Keynes foram, em grande medida, geradas na convivência com o Grupo de Bloomsbury - sob influência do filósofo G.E. Moore. O autor ressalta o viés antimaterialista de suas crenças juvenis: “[...] nossa religião era inteiramente não mundana [unworldly] — não tinha qualquer preocupação que fosse com riqueza, poder, popularidade ou sucesso[...] " Keynes, [1938], 1972, p. 437). Para o grupo, "[...] os fins principais na vida eram o amor, a criação e o aproveitamento de experiências estéticas, e a busca do conhecimento" (Keynes, [1938], 1972, pp. 436-7). E estes valores marcaram, de forma indelével, o 'olhar' do autor sobre o capitalismo.

${ }^{18}$ Uma das poucas coisas que Keynes admirava no comunismo russo era a sua proposta de construir uma ordem social na qual seria dado um peso bem menor ao amor ao dinheiro (Keynes, [1925a], 1972, pp. 259-60). Nela as atividades de 'fazer dinheiro' e 'acumular dinheiro' não seriam bem-aceitas, o que, por si só, seria uma "tremenda inovação" (Keynes, [1925a], 1972, p. 261).
} 
desfrutar das benesses que essa riqueza poupada possibilitava, era extremamente arraigada na população. ${ }^{19}$ Isso certamente representava, no âmbito de sua teoria econômica, um potencial problema para a manutenção de um alto nível de emprego, mas ele encarava essa atitude 'acumuladora', antes de tudo, como um problema moral.

Como aponta Goodwin (2006), no entender de Keynes, a sociedade 'civilizada' deveria garantir uma sobrevivência biológica confortável aos seus membros, e direcionar os recursos restantes ao desenvolvimento daquilo que realmente era moralmente nobre e digno de apreço: as artes, a literatura, e o conhecimento científico. ${ }^{20}$

O capitalismo era valorizado por ser capaz de garantir o requerido conforto material que viabilizaria o desenvolvimento das outras esferas da vida humana, e nunca como um fim em si mesmo (Backhouse \& Bateman, 2009, pp. 663-4). ${ }^{21} \mathrm{E}$ a busca desenfreada por riqueza pela riqueza (ou o instinto de querer ter mais do que os outros) acabaria por bloquear o desenvolvimento dos aspectos da vida que o autor prezava acima de tudo.

Sendo assim, Keynes certamente não simpatizava em termos morais com a figura do poupador/acumulador, que buscava incessantemente riqueza (Skidelsky, 1992, p. 542; Brittan, 2006, p. 189) e a quem faltava capacidade de desfrutá-la. ${ }^{22}$ O materialismo vigente em sua sociedade representava, assim, uma distorção que afastava os indivíduos dos verdadeiros valores da vida e os tornavam incapazes de "[...] passar virtuosamente e bem a hora e o dia, [e de valorizar] as pessoas agradáveis capazes de ter prazer direto nas coisas, os lírios do campo, que não mourejam nem fiam [...]" (Keynes, [1930], 1972, p. 331) - e essa incapacidade era vista como uma importante limitação moral ou de caráter. ${ }^{23}$

\footnotetext{
${ }^{19}$ Goodwin (2000) ressalta o papel atribuído pelo autor aos mitos na era vitoriana (em especial ao da expulsão de Adão e Eva do Paraíso) na disseminação de ansiedade e medo (ambos irracionais) em relação à escassez - que estariam subjacentes tanto ao afã de poupar como à incapacidade de aproveitar o presente. Na interpretação de Keynes, no período pré Primeira Guerra Mundial, “[a] moral, a política, a literatura, e a religião da época se juntaram em uma grande conspiração para promover a poupança [...]." (Keynes, [1923], 1972, p. 62). E por conta de todas essas influências, "[o] dever de 'poupar' tornou-se nove décimos da virtude e o crescimento do bolo o objeto de verdadeira religião" (Keynes, [1924], 1971, p. 12).

${ }^{20}$ Apesar de Keynes não utilizar essa terminologia nos seus textos, na base das suas concepções estaria, segundo Goodwin (2006) e Backhouse and Bateman (2009), a divisão adotada por Roger Fry (companheiro de grupo de Bloomsbury) entre a 'vida real' ('actual life') e a 'vida imaginativa' ('imaginative life'). A primeira seria referente às atividades voltadas para a sobrevivência biológica, e a segunda às atividades voltadas às artes, literatura e busca do conhecimento.

${ }^{21}$ Nesse contexto, os economistas teriam um papel limitado a cumprir. Eles seriam "[...] 'os guardiões não da civilização, mas da possibilidade de civilização' [...] Os verdadeiros guardiões da civilização [...] seriam os artistas e escritores, com quem ele [Keynes] gastou a maior parte de sua vida" (Goodwin, 2006, p. 223).

${ }^{22}$ Ele trata com sarcasmo essa atitude de se postergar indefinidamente o momento de desfrute da riqueza. Sobre o homem prático, que busca sempre aumentar os seus ganhos, ele diz: “[...] [ele] não ama o gato, mas os gatinhos de seu gato; na verdade nem sequer os gatinhos, mas apenas os gatinhos dos gatinhos e assim por diante, para sempre, até o fim da gataria [...]" (Keynes, [1930], 1972, p. 330).

${ }^{23}$ Backhouse and Bateman citam uma passagem de Keynes que, como eles mesmos apontam, lembra muito
} 
Todavia, tal como os seus antecessores, ele vislumbra uma sociedade melhor. No seu caso seria uma situação de abundância econômica — que o capitalismo ajudaria a conquistar - que permitiria à sociedade abandonar os 'falsos' valores seguidos na época e a avaliar o código moral vigente com mais clareza. $\mathrm{O}$ amor ao dinheiro como posse, e não como meio de fruir a vida, passaria a ser encarado como o que Keynes acreditava que de fato era: “[...] uma morbidade um pouco fastidiosa, uma dessas tendências semicriminosas e semi-patológicas que se costuma confiar com arrepios aos especialistas em doenças mentais [...]” (Keynes, [1930], 1972, p. 329). A sociedade teria a liberdade de "[...] voltar a alguns dos mais seguros e garantidos princípios da religião e da virtude tradicional - de que a avareza é um vício, a usura uma contravenção [...]" (Keynes, [1930], 1972, pp. 330-1), e os verdadeiros valores humanos poderiam, enfim, depois de quase 200 anos, voltar a pautar a vida social: "Valorizaremos novamente os fins acima dos meios, e preferiremos o bem ao útil. [...]”(Keynes, [1930], 1972, p. 331).

No entanto, apesar de deixar claro que rejeita os valores do capitalismo, Keynes, tal como os seus antecessores, via uma grande utilidade nesse código de ética 'distorcido' e considerava um risco abandoná-lo de uma hora para outra. A mudança de valores deveria ocorrer, mas não na sua geração, e sim naquela de seus netos. Nesse sentido, ele alerta seus leitores:

[...] cuidado! Ainda não chegou a hora. Pois, pelo menos por mais cem anos, precisamos fingir para nós mesmos e para os outros que o justo é o mau e o mau o justo; pois o mau é útil e o justo não. Ainda por algum tempo os nossos deuses continuarão sendo a avareza, a usura e a precaução. Pois somente eles poderão conduzir-nos dentro de dentro do túnel da necessidade econômica para a luz. (Keynes, [1930], 1972, p. 331)

\section{Keynes e a distribuição vigente de renda e riqueza}

Keynes, também parece se alinhar aos seus predecessores no reconhecimento do fato de o capitalismo, por si só, não conseguir engendrar uma distribuição satisfatória de renda e riqueza, e de não ser capaz de sanar o problema da pobreza.

$\mathrm{Na}$ Teoria Geral, ele aponta os principais defeitos do capitalismo como sendo o "[...] seu fracasso em prover o pleno emprego e as arbitrárias e não equitativas distribuições de renda e riqueza" (Keynes, [1936], 1973, p. 372).

No contexto da década de 1930 a questão do desemprego parecia ao autor muito mais premente e central - e de maior relevância para mitigar a pobreza do que as questões distributivas, e ele certamente empenhou-se com mais afinco para desenvolver meios para garantir o pleno emprego (Robinson, 1964, p. 6).

a avaliação de J.S. Mill sobre o capitalismo: "O espetáculo dos capitalistas, lutando para se tornarem líquidos [...], ou seja, empurrando os seus amigos e colegas para dentro do riacho gelado [chilly stream], para serem em seguida empurrados por trás por algum outro companheiro precavido [by some yet cautions fellow] não é uma visão edificante” (Keynes apud Backhouse \& Bateman, 2009, p. 662). 
Como o diagnóstico de Keynes sobre as causas do desemprego e pobreza era diferente daquele de J.S. Mill e Marshall, as políticas que ele propunha para minorar os problemas nesse campo também diferiam bastante daquelas demandadas pelos seus antecessores. ${ }^{24} \mathrm{Se}$ a ênfase desses autores recaía sobre a necessidade de intervenções pontuais do Estado no sentido de alterar algumas leis que regiam direitos de propriedade (leis de herança, apropriação da terra), contratos, e sobre o imperativo de efetuar em políticas sociais, como intervir na educação ou combater a pobreza e a desigualdade, o foco de Keynes é o de assegurar uma intervenção eficiente do Estado no sentido de garantir o pleno emprego.

Todavia, apesar de não ser a sua preocupação central, Keynes julgava desejável tornar a distribuição mais equitativa. Ele deixa claro em várias passagens que, tal como J.S. Mill e Marshall, acreditava que as desigualdades existentes eram desnecessariamente grandes e não remuneravam esforços ou sacrifícios reais:

[...] acredito que existem justificativas psicológicas e sociais para desigualdades significativas de riqueza e renda, mas não para as grandes disparidades hoje existentes. Existem valiosas atividades humanas que requerem o motivação do lucro [money-making motive] [...] Mas não é necessário para o estímulo dessas atividades [...] que o jogo seja jogado com apostas tão elevas como no presente. (Keynes [1936], 1973, p. 374, ênfase adicionada).

Keynes considerava a redução das 'apostas' importante inclusive para viabilizar a continuidade do capitalismo, pois essa situação de iniquidade poderia minar a estabilidade social. Na sua interpretação, no período que antecedeu a Primeira Guerra Mundial a desigualdade na distribuição teria sido o fundamento do ritmo de crescimento da riqueza sem precedentes que se observou, e que, de alguma forma a justificava socialmente. O homem de negócios era visto como alguém que servia à sociedade ao se abster do consumo de sua riqueza e acumulá-la (Keynes, [1924], 1971, p. 11-13). No entanto, no pós-guerra, os ganhos fáceis advindos da inflação teriam modificado a atitude do homem de negócios, que 'perde seu instinto de conservação' e passa a buscar ganhos excepcionais temporários ao invés de se preocupar com os lucros normais de longo prazo. Com isso, a sua figura, que no século anterior era louvada, passa ser vista com desconfiança crescente pela sociedade - o que poderia colocar em risco a própria existência do sistema vigente (Keynes, [1923], 1972, p. 68-9). ${ }^{25}$

\footnotetext{
${ }^{24}$ A questão de garantir o pleno emprego não era central para Mill e Marshall pelo fato de aderirem à Lei de Say. No entanto, Marshall admite a existência de desemprego por conta de crises comerciais, e defende auxílio fora de casas de trabalho [out-door relief] para aqueles trabalhadores responsáveis e previdentes que, porventura, perdessem os seus empregos (Groenewegen, 1995, pp. 150 e 355).

25 "Nenhum homem que se preze concordará em permanecer pobre se acredita que os que estão em melhores condições ganharam os seus bens por meio de apostas sortudas [Lucky gambling]. Converter o homem de negócios em um explorador [profiteer] é dar um golpe no capitalismo, uma vez que destrói
} 
O autor faz questão de frisar que sua teoria abria um amplo espaço para melhorias distributivas. Na sua interpretação, na teoria dos 'Clássicos' a poupança (dos ricos) era vista como essencial para o investimento - assim, a melhora da distribuição de renda ou riqueza era encarada como um eventual risco para a acumulação, e teria que se dar dentro de limites bem estreitos (Keynes, [1936], 1973, pp. 372-3). Para Keynes, ao contrário, o aumento da riqueza na época, “[...] longe de ser dependente da abstinência dos ricos [...] é, com maior probabilidade, tolhida por ela. Assim, uma das principais justificativas sociais para a grande desigualdade de riqueza é eliminada [...]" (idem, p. 373). ${ }^{26}$

Dessa forma, é possível afirmar que a insatisfação com o status quo, a crença de que no aspecto distributivo o capitalismo não engendrava espontaneamente bons resultados, e a vontade de intervir para mitigar os problemas são pontos comuns aos três autores.

\section{Keynes, o Estado e o fim do laissez-faire}

O próximo aspecto a ser discutido me parece mais polêmico que os demais. Será que também no que concerne ao papel do Estado vis-à-vis o mercado é possível filiar Keynes à tradição anterior? Ou teria havido uma mudança tão drástica de perspectiva sobre qual seria o critério de intervenção do Estado, e sobre as possíveis virtudes associadas a um sistema embasado na livre iniciativa, que impossibilitaria alinhar esses três autores no que diz respeito a esse ponto?

A questão do papel do Estado pode ser considerada um grande divisor de águas entre Keynes e os 'Clássicos'. De fato, J.S. Mill e Marshall, como vimos, defenderam a iniciativa individual e a política de não intervenção como as melhores formas de resolver os principais problemas econômicos e sociais. Keynes, por sua vez, decreta, já em 1926, o fim do laissez-faire, e questiona fortemente a capacidade de o mercado dar conta de resolver os principais problemas do capitalismo, ou de sequer ser capaz de garantir a sua sobrevivência enquanto sistema.

Em uma referência à confiança de Marshall no "[...] mestre individualista [o Capitão de Indústria] que nos serve ao servir-se a si mesmo, exatamente como faz qualquer outro artista” (Keynes, [1926b], 1972: p. 287), Keynes afirma que este

o equilíbrio psicológico que permite a perpetuação de recompensas desiguais [...]. O homem de negócios só é tolerável na medida em que os seus ganhos possam ser entendidos como tendo alguma relação com o que [...] a sua atividade contribuiu para a Sociedade” (Keynes, [1923], 1972, p. 69).

${ }^{26}$ Marshall critica a Economia Política Clássica pelo fato de supor que somente os capitalistas poupam. Ele argumenta que também as classes médias o fazem e aplicam essa poupança na educação dos filhos - o que contribuiria para o crescimento econômico tanto quanto a aplicação em capital físico feita pelos capitalistas. Assim, tal qual Keynes, ele acreditava que existia algum espaço para a distribuição de renda sem colocar em risco o aumento de riqueza (Marshall, [1920], 1982, p. 191). No entanto, é evidente que a ideia de que redistribuir renda para aqueles com maior propensão a consumir poderia levar a um crescimento da riqueza é mais radical, e abre um campo bem maior para a redistribuição de renda. Ainda assim, vale ressaltar que o problema da iniquidade mobilizou e incomodou bem menos a Keynes do que a Marshall e J.S. Mill — que lutaram com mais ardor para resolvê-lo. 
“[...] está se transformando num ídolo caído. Temos cada vez mais dúvidas sobre se é ele que nos conduzirá ao paraíso pela mão"(idem). ${ }^{27}$

O autor questiona diretamente as principais crenças relacionadas ao laissez-faire. Para ele:

[...] O mundo não é governado de forma que o interesse particular e o social sempre coincidam [...] Não constitui uma dedução correta dos princípios da Economia que o autointeresse esclarecido sempre atua a favor do interesse público. Nem é verdade que o autointeresse seja geralmente esclarecido [...] A experiência não mostra que os indivíduos, quando integram um grupo social, são sempre menos esclarecidos do que quando agem separadamente. (Keynes, [1926b],1972, pp. 287-8, ênfase no original)

A sua conclusão é a de que a doutrina do laissez-faire carece de embasamento racional e tem governado "[...] mais por direito hereditário do que por mérito pessoal"(Keynes, [1926b], 1972, p. 287).

Apesar dessa rejeição feroz à doutrina do laissez-faire, considero que, como abordagem geral à questão, Keynes não difere tanto dos seus antecessores como à primeira vista pode parecer. Com essas afirmações ele está combatendo uma concepção que se alastrou pela sociedade inglesa, não tanto por conta dos trabalhos de J.S. Mill e Marshall, mas por meio de obras de vulgarização e divulgação de Economia Política (como os escritos da Miss Marcel e da Miss Martineau), que eram muito populares no século XIX, e que encontraram respaldo em alguns políticos que tinham interesses específicos associados a esse tipo de postura do Estado. O próprio autor frisa que o laissez-faire dogmático não foi advogado por nenhum dos grandes economistas britânicos (Keynes, [1926b], 1972, pp. 278-282) — assim, as críticas têm outro alvo.

De toda forma, é inegável que, dado o diagnóstico de Keynes sobre o funcionamento de uma economia monetária e a sua percepção de que o mercado falhava em resolver problemas importantíssimos no campo econômico, o papel que ele delegou ao Estado nessa esfera foi maior do que aquele defendido por J.S. Mill e Marshall. Ainda assim, considero que a perspectiva geral de Keynes sobre qual seria o papel do Estado não difere de forma significativa daquela de seus antecessores. Esses três economistas assumem a postura de que seria desejável deixar à livre iniciativa e ao mercado aquelas esferas nas quais engendram bons resultados sociais, e de atribuir ao Estado o papel de agir naquelas esferas que em estes falhavam.

Tal como J.S. Mill e Marshall, Keynes parece acreditar que, quando os resultados obtidos são igualmente bons (ou mesmo apenas aproximadamente similares),

\footnotetext{
${ }^{27} \mathrm{Na}$ mesma linha, Keynes afirma em artigo sobre a Rússia: "Costumávamos acreditar que o capitalismo moderno seria capaz [...] de nos levar gradualmente em direção a um paraíso econômico [...] Agora temos dúvidas sobre se o homem de negócios está nos levando a um destino muito melhor do que aquele no qual nos encontramos no presente [...]” (Keynes, [1925a], 1972, p. 268).
} 
é preferível deixar a responsabilidade por conta da iniciativa privada do que jogá-la para o Estado. Só que ele conclui que em termos econômicos o laissez-faire e o individualismo seriam ineficientes e levariam o capitalismo à autodestruição. As técnicas que ele propõe para 'administrar' o capitalismo buscam, basicamente, tornar esse sistema econômica e socialmente viável.

Em momento algum Keynes propõe abrir mão da iniciativa privada. Apesar da sua crítica moral a alguns valores do capitalismo, há vários aspectos da sua sociedade que ele parece admirar e julgar importante manter. Para ele, tal como a tradição que o antecede, preservar um grande espaço para a ação individual seria a melhor garantia de liberdade, da diversidade e do progresso social. Isso fica claro em uma passagem — que lembra muito o On Liberty de J.S. Mill — onde afirma:

[...] acima de tudo, individualismo, se puder ser purgado de seus defeitos e abusos, é a melhor salvaguarda da liberdade pessoal no sentido de que, comparado com qualquer outro sistema, expande grandemente o campo para o exercício da escolha pessoal. É também a melhor salvaguarda da variedade da vida, que emerge justamente desse campo ampliado de escolha pessoal, e cuja perda é a maior das perdas associadas ao Estado homogêneo ou autoritário. Pois essa diversidade preserva as tradições que incorporam as escolhas mais seguras e bem-sucedidas das gerações precedentes; dá cor ao presente com a variedade de sua fantasia [fancy]. E [...] é o mais poderoso instrumento para melhorar o futuro [...] (Keynes, [1936], 1973, p. 380 $)^{28}$

Ele frisa, recorrentemente, que o Estado não deve tentar substituir a iniciativa privada, mas somente gerar uma situação na qual esta possa funcionar de forma eficiente. Tal como os demais autores aqui tratados, ele advogava que o Estado deveria atuar somente onde o mercado 'falha':

[...] a mais importante Agenda do Estado não diz respeito às atividades que os indivíduos particularmente já realizam, mas às funções que estão fora do âmbito individual, àquelas decisões que ninguém adota se o Estado não o faz. Para o governo, o mais importante não é fazer coisas que os indivíduos já estão fazendo, e fazê-las um pouco melhor ou um pouco pior, mas fazer aquelas coisas que atualmente deixam de ser feitas. (Keynes, [1926b], 1972, p. 288)

Só que, no entender de Keynes, o mercado fracassava em pontos cruciais da vida econômica - como, por exemplo, em garantir o pleno emprego -, portanto, também nesse aspecto o Estado deveria atuar. Ele buscava, e julgava ter encontra-

\footnotetext{
${ }^{28}$ Sobre a postura de Keynes em relação ao individualismo, Brittan indaga: "Era Keynes um individualista? (Brittan, 2006, p. 190). E responde afirmativamente: "Na esfera pessoal, ele o era em grau extremo"(idem).
} 
do, uma técnica de administrar o sistema econômico (que envolvia uma grande dose de participação do Estado) que fosse capaz de resolver o problema do desemprego, da baixa produção, da extrema desigualdade de renda e riqueza, etc., sem sacrificar os valores - com os quais ele se identificava — de liberdade individual e diversidade de modos de vida. Da forma como ele o concebe, "[o] problema político da humanidade é combinar três coisas: eficiência econômica, justiça social e liberdade individual" (Keynes, [1926a], 1972, p. 311) - que era justamente o problema que Mill e Marshall buscavam resolver. ${ }^{29}$

Assim, apesar de pregar mudanças no campo de atuação do Estado, o ideário de Keynes não difere muito, no meu entender, daquele de seus predecessores, sendo, em princípio, defensável alinhá-los também no que diz respeito a esse ponto. ${ }^{30}$

\section{Keynes e a mudança social}

No que concerne à concepção mais geral de mudança social também é possível encontrar similaridades importantes entre as abordagens de J.S. Mill e Marshall e aquela de Keynes. Este último, como vimos, também vislumbrava a possibilidade de o capitalismo, se bem administrado, tornar-se um sistema mais eficiente e justo, sem a necessidade de sacrifícios da liberdade. Ademais, julgava que essa modificação na ordem vigente poderia (e deveria) ocorrer de forma gradual, sem rupturas radicais na ordem vigente.

Keynes, à semelhança dos outros dois autores, rejeita as alternativas existentes à sua época que visavam a substituir a ordem vigente e, apesar de ver inúmeros defeitos em seu funcionamento, buscava uma transformação, mantendo-se dentro do marco institucional básico do capitalismo inglês da época, de democracia, propriedade privada e competição no mercado. ${ }^{31}$

De fato, Keynes atribui um papel bem mais amplo ao Estado do que os economistas precedentes, no entanto, nunca advogou (ou aceitou) a ação totalitária do Estado - que ele identificava tanto no fascismo como no comunismo - na resolução dos problemas econômicos e sociais. Caberia, sim, ao Estado intervir

\footnotetext{
29. Keynes parece dar tanto valor à liberdade quanto Hayek - seu oponente no campo da Economia. Sobre O Caminho da Servidão, ele afirma: "[...] Moral e filosoficamente eu me acho em acordo com ele, mas não somente de acordo, mas em profundo e emocionado acordo [a deeply moved agreement]." (Keynes apud Christainsen, 1993, p. 50). Brittan (2006, p. 196) argumenta que no coração das divergências entre Keynes e Hayek estava, justamente, a concepção de Keynes de que a liberdade individual era compatível com um nível maior de planejamento e intervenção estatal do que Hayek estava disposto a admitir.

${ }^{30}$ Como afirma Vercelli: "Keynes sempre considerou o liberalismo econômico uma doutrina em mutação [evolving doctrine] que tinha que ser continuamente atualizada para dar conta dos novos desenvolvimentos na teoria e nos fatos. Na sua obra-prima, ele visou a dar uma contribuição importante para a sua atualização e não para o seu fim, como alguns interpretes erroneamente acreditam” (Vercelli, 2010, p. 65).

${ }^{31}$ Como nota Skildesky: “[a] depressão radicalizou Keynes em termos intelectuais, mas não em termos políticos ou sociais” (Skidelsky, 1992, p. 437).
} 
na vida econômica de forma a dar 'racionalidade' ao sistema capitalista. Ele deveria exercer influência sobre o nível agregado de consumo e investimento por meio de impostos, fixação de taxa de juros e, em alguma medida, empreender a socialização dos investimentos de forma a garantir uma situação próxima ao pleno emprego. ${ }^{32}$ Mas isso de forma alguma envolveria a propriedade estatal ou gestão centralizada dos meios de produção:

Se o Estado for capaz de determinar o volume agregado de recursos destinados a aumentar esses instrumentos [de produção] e as taxas básicas de remuneração de seus proprietários, já terá feito tudo que é necessário. (Keynes, [1936], 1973, p. 378)

Além desse ponto não seria preciso (nem desejável) avançar no caminho de socialização da vida econômica. E, segundo ele, essas medidas necessárias de socialização poderiam ser introduzidas "[...] gradualmente sem ruptura nas tradições generalizadas da sociedade”(Keynes, [1936], 1973, p. 378) - o que era visto como uma enorme vantagem. ${ }^{33}$

Embora tenha assumido uma atitude reformista em relação ao sistema capitalista, Keynes parecia acreditar que grandes mudanças poderiam advir desse tipo de intervenção na ordem social. Além de resolver o problema do desemprego e ineficiência, com a adoção de políticas econômicas adequadas seria possível acabar com a escassez de capital e se chegar a uma situação mais justa no sentido de as remunerações obtidas passarem a ter alguma relação com sacrifícios envolvidos na produção (Keynes, [1936], 1973, p. 376). O caráter de rentier do capitalismo seria extinto, “[...] de modo que o investidor sem função não receba mais qualquer benefício [...]" (Keynes, [1936], 1973, p. 376) - o que além de diminuir a iniquidade do sistema, aumentaria a sua legitimidade que, como vimos, passou a ser questionada no pós-Primeira Guerra Mundial. E tudo isso sem quebras abruptas na ordem vigente:

[...] uma grande vantagem da ordem de acontecimentos que advogo é que a eutanásia do rentier, do investidor sem função, não será repentina, mas meramente uma gradual e prolongada continuação do que tem sido observado recentemente na Grã-Bretanha, e não irá requerer qualquer revolução. (Keynes, [1936], 1973, p. 376).

\footnotetext{
${ }^{32} \mathrm{Na}$ interpretação de Skidelsky (1997, p. 434), ‘socialização do investimento’ queria dizer, para Keynes, o crescimento da parcela do investimento controlado por instituições cujas ações estavam mais atreladas ao interesse social do que à obtenção do lucro no curto prazo. Essas instituições não seriam necessariamente públicas. Um bom exemplo de instituição privada com esse perfil seria o Banco da Inglaterra.

${ }^{33}$ Baldwin (2006, p. 251) relaciona a posição moderadamente conservadora de Keynes no que concerne à mudança institucional à sua concepção de como os agentes decidiam em contexto de incerteza. Medidas radicais poderiam minar a (já frágil) confiança dos investidores. Assim, o autor sugere que, para Keynes, "[...] a eficiência econômica requer o respeito às instituições da propriedade e ao governo das leis"(Baldwin, 2006, pp. 254-5).
} 
Dessa forma, com a adoção de novas 'técnicas' no campo da Economia seria possível dirimir alguns dos traços mais objetáveis do sistema econômico da época e ainda preservar um grande espaço para a iniciativa e liberdade individuais. As condições estariam, então, colocadas para a superação (no futuro) do 'problema econômico' e para que a humanidade saísse, por fim, do "túnel da necessidade econômica para a luz" (Keynes, [1930], 1972, p. 331). Nessa situação de abundância, viabilizada pelo capitalismo 'reformado', seria possível abandonar sem riscos os antigos 'deuses' da avareza, usura e precaução e, finalmente, desfrutar a 'boa vida' - que Keynes valorizava acima de tudo. ${ }^{34}$

Assim, tal como os outros autores tratados, Keynes parecia crer que seria possível modificar - com a ajuda da ciência econômica — de forma significativa a realidade (e os valores) de sua época, sem a necessidade de revolucionar as tradições ou as principais instituições sociais existentes. E ele, tal como J.S. Mill e Marshall fizeram anteriormente, buscou incansavelmente formas de conduzir a sociedade em direção a essa ordem social que considerava superior.

\section{CONSIDERAÇÕES FINAIS}

É sempre problemático falar em uma "tradição" ou uma linhagem unindo diferentes pensadores (principalmente quando se trata de autores do porte dos escolhidos neste artigo). Tenho consciência de que da mesma forma que foram exploradas algumas semelhanças entre as filosofias sociais e econômicas de J.S. Mill, Marshall e Keynes, seria possível escrever outro trabalho explicitando os aspectos e as nuances que as separam - e posso atestar que são inúmeros.

No entanto, acho interessante frisar as continuidades existentes em termos da perspectiva geral em relação ao capitalismo e de reforma social principalmente por considerar que a ruptura que geralmente se enfatiza entre as concepções de Keynes e aqueles que ele denomina "Clássicos" é superestimada.

Há várias razões para que isso ocorra. Em primeiro lugar, os economistas que ainda se dão o trabalho de estudar a obra de Keynes (que são cada vez mais raros) em geral defendem teorias 'heterodoxas', e se encontram em um campo de batalha teórico e em termos de políticas econômicas com a 'ortodoxia neoclássica' - que é associada às concepções neoliberais que vigoraram nas últimas décadas. É natural, portanto, que queiram frisar os aspectos que separam Keynes de autores vinculados ao liberalismo econômico como J.S. Mill e Marshall. Em segundo lugar, até por uma questão da formação atual do economista, o olhar daqueles que analisam os economistas do passado se restringe, muitas vezes, aos elementos que caem estritamente no que se considera hoje em dia o 'campo do econômico'. Esse campo

\footnotetext{
${ }^{34}$ Como enfatiza Chick: "Para Keynes, a atividade econômica era meramente um meio para o fim: a boa vida, na qual se teria tempo para 'amizades e para a contemplação de objetos belos'. Ele se contentava com a economia do suficiente [economics of enough] — o suficiente para prover para as necessidades, de forma que as coisas boas da vida pudessem ser aproveitadas" (Chick, 2013, p. 36).
} 
abrange a teoria econômica e as políticas econômicas (fiscal, monetária, cambial, etc.), mas não as questões de filosofia social e econômica que ao longo do século XIX e começo do século XX ainda povoavam os compêndios de Economia - para as quais os três economistas deram importantes contribuições. Como na esfera estritamente econômica as diferenças entre as abordagens de Keynes e aquela de J.S. Mill e Marshall predominam, é normal que se enfatize o lado da ruptura. ${ }^{35}$

Todavia, se olharmos apenas por esse prisma, corremos o risco de perder de vista que J.M. Keynes pode ser filiado a uma tradição no campo da reforma econômica e social que visa a melhorar o sistema capitalista vigente de foram gradual, sem solapar as suas bases de forma abrupta; que deseja uma sociedade mais eficiente, mais justa e moralmente mais elevada, mas que considera um risco enorme para o progresso humano e social abrir mão da liberdade e da diversidade - com isso, esses importantes aspectos do seu pensamento podem passar despercebidos.

\section{REFERÊNCIAS BIBLIOGRÁFICAS}

BACKHOUSE, R.E \& BATEMAN, B.W. (2009) “Keynes and Capitalism”. HOPE, vol. 41, n. 4.

BALDWIN, T. (2006) “Keynes and ethics”. In Roger Backhouse \& Bradley Bateman, The Cambridge Companion to Keynes. Cambridge: Cambridge University Press.

BOWMAN, R. (2004) "Marshall: Just how interested in doing good was he?", Journal of the History of Economic Thought, vol. 25, n. 4, pp. 492-518.

BRITTAN, S. (2006) “Keynes's political philosophy”. In Roger Backhouse \& Bradley Bateman, The Cambridge Companion to Keynes. Cambridge: Cambridge University Press.

CHICK, V. (2013) "Economics and the good life: Keynes and Schumacher.” Economic Thought, vol. 2 n. 2 .

CHRISTAINSEN, G.B. (1993) "What Keynes really said to Hayek about planning”, Challenge, vol.36, n. 4.

CORRY, B. (1978) “Keynes in the history of economic thought”. In A.P. Thirlwall, ed. Keynes and Laissez-faire. London: Macmillan.

GOODWIN, C. D. (2000) "Economic man in the garden of Eden", Journal of the History of Economic Thought, vol. 22, issue 4.

GOODWIN, C. D. (2006) “The art of an ethical life”. In Roger Backhouse \& Bradley Bateman, eds. The Cambridge Companion to Keynes. Cambridge: Cambridge University Press.

GRAMPP, W.D. (1972) “Classical Economics and moral critics”, History of Political, vol. 5, n. 2.

GROENEWEGEN, P. (1995) “Keynes and Marshall: Methodology, society and politics”. HOPE, vol. 27 pp. $129-155$.

GROENEWEGEN, P. (1995) A Soaring Eagle: Alfred Marshall 1842-1924. Aldershot: Edward Elgar. HUTCHISON, T.W. (1969) “Economists and economic policy in Britain after 1870", HOPE, vol. I, n. 2. KEYNES, J.M. [1923] (1972) "Social consequences of changes in the value of money". In Essays in Persuasion, The Collected Writings of John Maynard Keynes, vol. IX. London: Cambridge University Press.

KEYNES, J.M. [1924] (1971) “The cconomic consequences of the Peace”. In The Collected Writings of John Maynard Keynes, vol. II, London: Macmillan and Cambridge University Press for the Royal Society.

\footnotetext{
${ }^{35} \mathrm{Na}$ esfera da teoria econômica não faz nem sentido falar de uma tradição que una J.S. Mill e Marshall.
} 
KEYNES, J.M. [1925] (1966) “Alfred Marshall, 1842-1924”. In A.C. Pigou, ed., Memorials of Alfred Marshall. New York: Kelley.

KEYNES, J.M. [1925a] (1972) "A short view of Russia” In Essays in Persuasion, The Collected Writings of John Maynard Keynes, vol. IX, London: Macmillan and Cambridge University Press.

KEYNES, J.M. “Liberalism and labour” [1926a](1972) In Essays in Persuasion, The Collected Writings of John Maynard Keynes, vol. IX. London: Macmillan and Cambridge University Press.

KEYNES, J.M. [1926b] (1972) "The end of laissez-faire". In Essays in Persuasion, The Collected Writings of John Maynard Keynes, vol. IX, London: Macmillan and Cambridge University Press.

KEYNES, J.M. [1930] (1972) "The economic possibilities of our grandchildren". In Essays in Persuasion, The Collected Writings of John Maynard Keynes, vol. IX, Macmillan and Cambridge University Press.

KEYNES, J.M. [1936] (1973) “The general theory of employment, interest and Money”. In Collected Writings of John Maynard Keynes, vol. VII. London: Macmillan St.Martin's Press for the Royal Economic Society.

KEYNES, J.M. [1938] (1972). “My early beliefs.” In Collected Writings of John Maynard Keynes, Vol. $\mathrm{X}$, Essays in Biography, chapter 39. London: Macmillan St.Martin's Press for the Royal Economic Society.

MARSHALL, A. [1873] (1966) “The future of the working classes”. In A.C. Pigou, ed., Memorials of Alfred Marshall. New York: Kelley.

MARSHALL, A. [1890] (1966) “Some aspects of competition”. In A.C. Pigou, ed., Memorials of Alfred Marshall. New York: Kelley.

MARSHALL, A. [1889] (1966) “Co-operation”. In A.C. Pigou, ed., Memorials of Alfred Marshall. New York: Kelley

MARSHALL, A. [1920] (1982) Principles of Economics. Pennsylvania: Porcupine Press.

MARSHALL, A. [1907], (1966) “The Social Possibilities of Economic Chilvary" in A.C. Pigou, ed., Memorials of Alfred Marshall. New York: Kelley.

MATTOS, L.V. (1999) “John Stuart Mill, o socialismo e sua utopia liberal: Uma aplicação de sua visão de instituições sociais”, Estudos Econômicos, vol. 29, n. 3, pp. 395-414.

MATTOS, L.V. (2008) "Rumo a uma sociedade melhor: uma análise da agenda de reformas econômicas de J.S. Mill.”, Estudos Econômicos, vol. 38, pp. 293-317.

MATTOS, L.V. (2011) "Marshall, o capitalismo e sua utopia social”. Economia e Sociedade, vol.20, n. 3 (43), p. 637-659.

MILL, J.S. [1848] (1965) Principles of Political Economy with some of their Applications to Social Philosophy. In CW II e III. Toronto: University of Toronto Press.

MILL, J.S. [1859]. (2000) “A Liberdade”. Em A Liberdade; Utilitarismo: John Stuart Mill. Tradução Eunice Ostrensky, São Paulo: Martins Fontes.

MILL, J.S. [1879] (1967) "Chapters on socialism". In Essays on Economics and Society, 1850-1879, CW V Toronto: University of Toronto Press.

PARSONS, T. (1931) "Wants and activities in Marshall”, in Quarterly Journal of Economics, 46: 101-40.

REISMAN, D. (1987) Alfred Marshall: Progress and Politics. London: Macmillan.

ROBINSON, J. (1964) "Marx, Marshall and Keynes — Three views of Capitalism”. In Joan Robinson Collected Economic Papers Vol. II. Oxford: Basil Backwell.

SKIDELSKY, R. (1992) John Maynard Keynes, Vol. Two: The Economist as Saviour — 1920-1937. London: Macmillan.

SKIDELSKY, R. (1997) “Keynes' 'concluding Notes'. In G.C. Harcourt and P.A. Riach, eds., A 'Second Edition' of the General Theory, vol. 1. London and New York: Routledge.

VERCELLI, A. (2010) “Mr Keynes and the 'Liberals”. In Robert W. Diamand, Robert A. Mundell and Alessandro Vercelli, eds., Keynes's General Theory After Seventy Years. New York: Palgrave Macmillan.

VINER, J. (1958) "Marshall's economics in relation to the man and to his times". In The Long View and the Short. Illinois: George Allen \& Unwin. 